\title{
Reply to Bellwood's Letter
}

\author{
Tsunehiko Hanihara \\ Department of Anatomy, Tohoku University School of Medicine, \\ 2-1 Seiryo-cho, Aoba-ku, Sendai 980-77, Japan
}

Received March 18, 1995

I recognize the use of unsuitable expressions which cause misunderstanding with my expression (Hanihara, 1993, p. 39, lines 1-2). In this point, I must apologize to P. Bellwood and others. My recent study (Hanihara, 1994) agrees with Bellwood's view that the people once lived in the southern part of present-China may have been populations with physical affinities to the present Southeast Asians, apart from the question of their center of origin in geographical sense.

I do not confuse the term "Chinese" and people once lived in the southern part of the present People's Republic of China. From the book written by Bellwood (1978), it may be possible to understand that his interpretation of the present Southeast Asian physical features is more or less attributed to genetic influence of East Asians including "Chinese" of the Han Nationality.

According to Bellwood (1985), the origin of the present Southeast Asians can be traced back to Austronesian speaking "Southern Mongoloid" in the prehistoric southern China. Concerning the origins and affinities of the "Southern Mongoloid," however, the description may allow us to interpret that his "Southern Mongoloid" is a hybrid population between "Australoid" and "Mongoloid" which includes the present "Chinese" and their direct ancestors, and the present Southeast Asia is a part of "Mongoloid" world of East Asia.

Brace and his colleagues emphasize that the term "Mongoloid" is a most inappropriate choice of terms to use for the people of eastern Asian origin (Li et al., 1991; Brace and Tracer, 1992). The use of ambiguous terms based only on the reason of classificatory simplicity may be a cause to confuse the interpretation of what writers actually state.

Regarding the criticism of my conclusion, I never conclude anything about new findings concerning the Southeast Asians from the results shown in the paper only (Hanihara, 1993). I wrote "This may be a sign of evolutionary divergence in.... The uniqueness of... herein is an additional support of the local evolution" (emphasis added). These mean that the results are not inconsistent with the pioneering studies by K. Omoto, C.G. Turner, M. Pietrusewsky and others, and my own preliminary studies.

\section{REFERENCES}

Bellwood, P. (1978) Man's Conquest of the Pacific: The Prehistory of Southeast Asia and Oceania, Oxford Univ. Press, New York.

Bellwood, P. (1985) Prehistory of the Indo-Malaysian Archepelago, Academic Press, Sydney. Brace, C.L., and Tracer, D.P. (1992) Craniofacial continuity and change: A comparison of late 
Pleistocene and recent Europe and Asia. In The Evolution and Dispersal of Modern Humans in Asia (Akazawa, T., Aoki, K., and Kimura, T., eds.), Hokusen-sha, Tokyo, pp. 439-471.

Hanihara, T. (1993) Craniofacial features of Southeast Asians and Jomonese: A reconsideration of their microevolution since the late Pleistocene. Anthropol. Sci. 101, 25-46.

Hanihara, T. (1994) Craniofacial continuity and discontinuity of Far Easterners in the late Pleistocene and Holocene. J. Hum. Evol. 27, 417-441.

Li, Y., Brace, C.L., Qiang, G., and Tracer, D.P. (1991) Dimensions of face in Asia in the perspective of geography and prehistory. Am. J. Phys. Anthropol. 85, 269-279. 